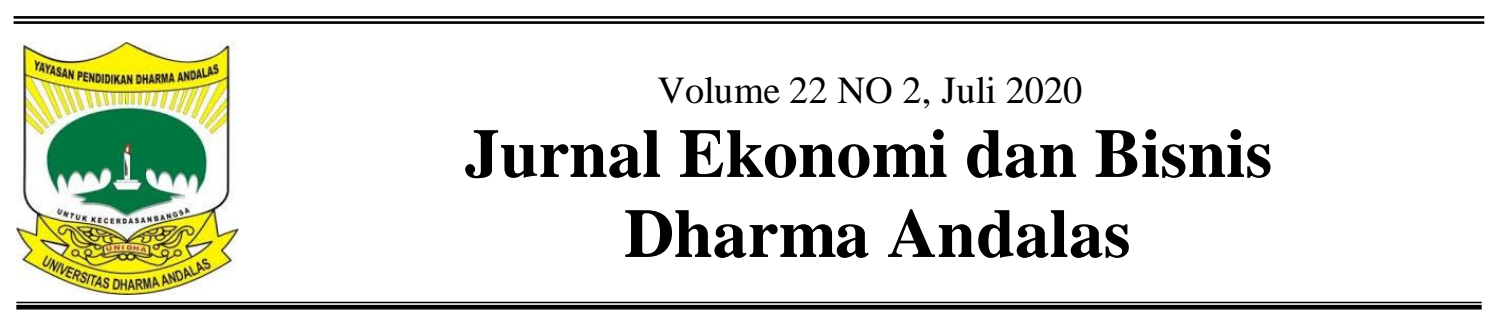

\title{
Pengaruh Celebrity Endorser Terhadap Keputusan Pembelian (Studi Pada Produk Erigo Melalui Instagram)
}

\author{
Tessa Surya Ningsih ${ }^{1}$, Siska Lusia Putri ${ }^{2}$ \\ Fakultas Ekonomi dan Bisnis, Universitas Dharma Andalas ${ }^{1,2}$ \\ siskalusiaputri@gmail.com
}

\begin{abstract}
The research is in the form of quantitative research using primary data obtained from the distribution of questionnaires. The study population included Instagram users who joined the @erigoapparel Instagram. Data obtained from collection throught onlilne distribution questionnaires to customers who have purchased Erigo products through Instagram and know Arief Muhammad as Erigo's brand endroser. The population data in this study were 100 respondents. The sampling technique used in purposive sampling. Methods analysis of the data used is multiple linear regression. The result showed that partially the trustworthiness, variabel had no significant effect on purchasing decisions, expertise did not have a significant effect on purchasing decisions, attractive had a significant effect on purchasing decision, respect did not significant influence purchasing decisions and similairty had a significant effect on purchasing decisions. Product Erigo the value of Adjust $R$ square. Product Erigo indicators by 0.539 .
\end{abstract}

Keyword: celebrity endorser, instagram social media, purchase decisions

\begin{abstract}
ABSTRAK
Penelitan ini berbentuk kuantitatif dengan menggunakan data primer yang diperoleh dari penyebaran kuisioner. Populasi penelitian ini meliputi pengguna instagram yang mengikuti akun instagram @erigoapparel dan konsumen yang pernah membeli produk Erigo. Data yang diperoleh dari pengumpulan melalui kuisioner online ke pelanggan yang telah membeli produk Erigo melalui Instagram dan mengenal Arief Muhammad sebagai endorser merek dari Erigo. Data populasi dari penelitian ini sebanyak 100 responden. Teknik pengambilan sampel yang digunakan adalah Purposive Sampling. Metode analisis data yang digunakan adalah regresi linier berganda. Hasil penelitian ini menunjukkan bahwa secara parsial variabel trustworthiness, tidak berpengaruh secara signifikan terhadap keputusan pembelian, expertise tidak berpengaruh signifikan terhadap keputusan pembelian, attractiveness berpengaruh signifikan terhadap keputusan pembelian, respect tidak berpengaruh signikan terhadap keputusan pembelian dan similiarity berpengaruh signifikan terhadap keputusan pembelian. Produk Erigo ini memiliki nilai Adjust $R$ square sebesar 0.539 .
\end{abstract}

Keyword: celebrity endorser, sosial media instagram, keputusan pembelian

\section{PENDAHULUAN}

Era modern saat ini, aplikasi smarthphone sangat membantu masyarakat dalam melakukan transaksi belanja online melalui media sosial instagram. Instagram yaitu sarana photo sharing yang saat ini digemari oleh pengguna media sosial di berbagai penjuru dunia termaksud Indonesia. Instagram juga mendukung pemasar karena banyak fitur unggulan yang dapat dimanfaatkan. Pada tahun 2018, Instagram mengalami peningkatan pengguna aktif bulanan sebanyak 1 
Miliar yang dapat menghabiskan waktu kunjung selama 257 menit per bulannya (kompas.com). Berdasarkan polling tahun 2016 dari jakpat, sebuah riset mobil, bahwa pengguna Instagram Indonesia mengikuti akun digital retailer sebanyak 56,2\%. Data tersebut menjelaskan bahwa Instagram menjadi peran yang dapat menghasilkan follower akun digital retailer serta dapat menciptakan peluang bagi unit kecil dan menengah dalam mempromosikan produk-produknya.

Instagram Users Ages 18-35 in Indonesia Who Follow Digital Retailers on Instagram, by Type, Jan 2016 \% of respondents

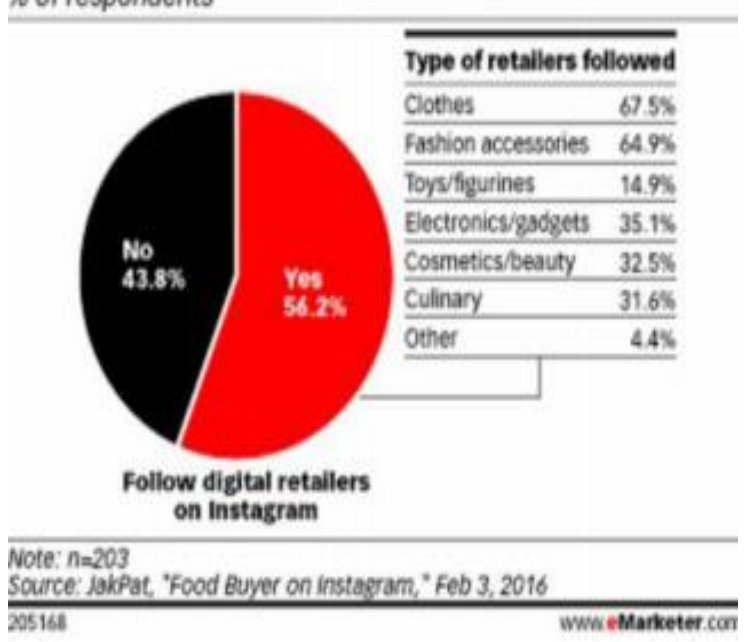

Sumber : e-marketer.com, 2016

Gambar 1.

\section{Grafik Pengguna Instagram}

Tidak hanya itu pelaku bisnis juga harus meningkatkan strategi pemasar agar dapat bersaing dengan kompetitor. Salah satu strategi pemasar yang dapat dikenal dalam dunia digital yaitu Celebrity Endorser. Peran Celebrity Endoser tersebut membantu dalam memberikan rekomendasi dan informasi kepada pengguna digital terkait produk yang dipakai walaupun produk tersebut tidak memiliki brand image terkenal. Berikut observasi awal yang melibatkan 30 followers Instagram @tesasry terhadap merek pakaian di Instagram yang mereka ketahui

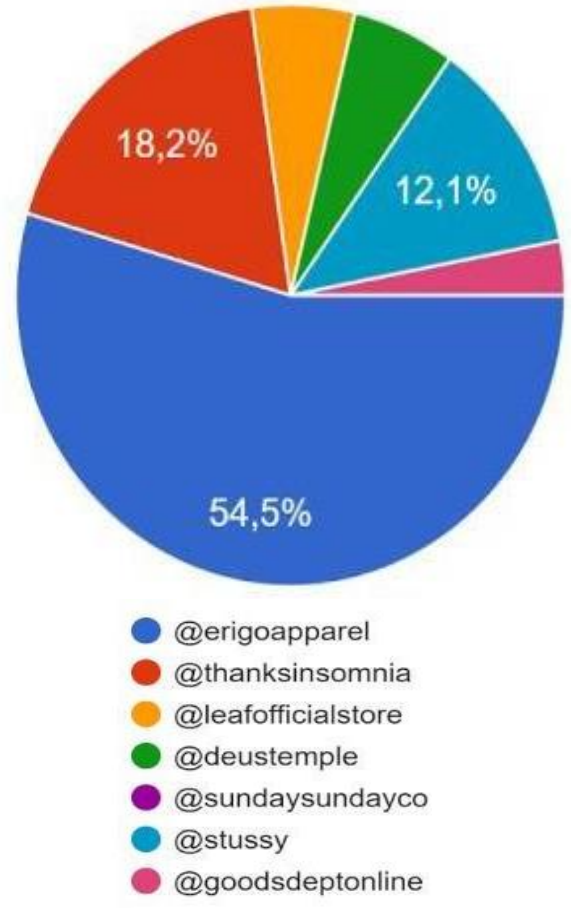

Sumber: Olahan Peneliti, 2019

Gambar 2

\section{Grafik Merek Fashion}

Dari gambar 2 dijelaskan bahwa ada 7 merek pakaian di Instagram yang memiliki Indikator yang sama, yakni : produksi berupa pakaian untuk travelling dan sejenisnya, pembelian melalui website, Instagram hanya sebagai media promosi. Berdasarkan gambar diatas, ada 3 merek tertinggi yaitu, Erigo 54,5\%, Thanksinsomnia18,2\%, Stussy $12,1 \%$. Dari ketiga data tersebut, peneliti memilih Erigo sebagai objek penelitian berlaanjut karena memiliki persentase yang lebih tinggi. Erigo merupakan toko pakaian yang fokus terhadap kebutuhan travelling dan sehari-hari. Produk yang dijual berupa t-shirt, loongsleeve, hoodie, sukajan, flannel, slingbag, sandal, shoes slip-on, chino pants, parka, striped, denim jacket, dan coach jacket. Produk Erigo juga dapat dipakai dikalangan pria maupun wanita.

Sebelum melanjutkan observasi terhadap merek Erigo, peneliti melakukan observasi terlebih dahulu kepada 30 pengguna akun Instagram yang mengikuti @erigoapparel dan konsumen yang pernah membeli produk 
Erigo tersebut. Berikut tanggapan mereka sewaktu ditanyakan pendapat meraka tentang produk tersebut :

\section{Tabel 1}

Tanggapan Followers dan Konsumen Pengguna Produk Erigo

\begin{tabular}{llccc}
\hline No & \multicolumn{1}{c}{ Penilaian Konsumen } & Setuju & $\begin{array}{c}\text { Tidak } \\
\text { Setuju }\end{array}$ & $\begin{array}{c}\text { Persentase } \\
\text { Setuju (\%) }\end{array}$ \\
\hline 1 & $\begin{array}{l}\text { Celebrity endorser menjadi } \\
\text { daya tarik saya dalam } \\
\text { membeli produk Erigo }\end{array}$ & 25 & 5 & $83.3 \%$ \\
$2 \quad \begin{array}{l}\text { Testimonial adalah salah } \\
\text { satu petunjuk saya dalam } \\
\text { mengambil keputusan } \\
\text { pembelian. }\end{array}$ & 13 & 7 & $43.33 \%$ \\
3 & $\begin{array}{l}\text { Saya tertarik belanja di Erigo } \\
\text { karena produk yang dijual } \\
\text { sesuai dengan tampilan } \\
\text { fashion masa kini. }\end{array}$ & 21 & 9 & $70 \%$ \\
4 & $\begin{array}{l}\text { Detail produk serta } \\
\text { prosedur pembelian yang } \\
\text { jelas akan mempengaruhi }\end{array}$ & & & \\
saya dalam mengambil \\
keputusan.
\end{tabular}

Sumber: Olahan Penliti, 2019

Berdasarkan Tabel 1 diperoleh jumlah persentase paling tinggi sebanyak $83.33 \%$ dimana pengguna Instagram membeli produk Erigo karena tertarik pada celebrity endorser yang digunakan oleh Erigo. Erigo memperkenalkan produknya lewat Arief Muhammad, yang dikenal sebagai Brand Influencer Instagram dan seorang content creator di youtube melalui karya vlog-nya hal tersebut yang membuat orang tetarik membeli produk Erigo terutama pada kalangan muda.

Melihat fenomena diatas, penulis tertarik untuk melakukan penelitian lebih lanjut pada Influencer Arief Muhammad sebagai Celebrity Endorser Erigo. Adapun indikator yang digunakan adalah dengan menggunakan lima dimensi yaitu trustworthiness (kepercayaan), expertise (keahlian), attractiveness (daya tarik), respect (kepedulian), dan similarity (kesamaan). didapatkan bahwa daya tarik mempunyai pengaruh yang paling kuat dibandingkan dengan variabel lainnya sehingga variabel daya tarik mempunyai pengaruh yang dominan terhadap keputusan pembelian.

Berdasarkan latar belakang diatas, maka rumusan masalah dalam penelitian ini adalah bagaimana pengaruh celebrity endorser (trustworthiness, expertise, attractiveness, respect dan similarity) secara parsial dan simultan terhadap keputusan pembelian produk Erigo melalui Instagram

Tujuan penelitian ini adalah menganalisis pengaruh celebrity endorser (trustworthiness, expertise, attractiveness, respect, dan similarity) terhadap keputusan pembelian produk Erigo melalui Instagram.

Promosi

Menurut Osman, Benjamin, dan Yeoh (2011): "Promosi adalah salah satu teknik untuk menarik konsumen untuk membeli lebih banyak atau mencoba produk atau jasa." Salah satu keuntungan dari promosi adalah dapat merangsang konsumen untuk berpikir dan mengevaluasi merek dan ada kemungkinan membeli ketika mereka tidak memiliki produk itu. Oleh karena itu, banyak pemasar dan pengecer memanfaatkan berbagai jenis alat promosi dan strategi untuk memahami preferensi konsumen dan meningkatkan penjualan mereka. (Osman, Benjamin, dan Yeoh, 2011).

Media Internet Internet adalah salah satu metode yang paling modern digunakan untuk bertukar serta menyebarkan informasi dan pengetahuan dengan biaya rendah (Alsarayreh dan Jawabreh, 2011).

Media online Menurut Iwan Awaluddin Yusuf di situs bincangmedia.wordpress.com (2010), Media online adalah sebutan umum untuk sebuah media yang berbasis telekomunikasi dan multimedia (komputer dan internet). Didalamnya terdapat portal, website (situs web), 
radio online, Tvonline, pers online, mailonline, dll, dengan karakteristik masingmasing sesuai dengan fasilitas yang memungkinkan user memanfaatkannya. Promosi melalui media internet

Iklan merupakan salah satu cara untuk melakukan promosi melalui media internet. Iklan online adalah bentuk promosi yang menggunakan internet dan World Wide Web untuk tujuan menyampaikan pesan memberikan pemasaran untuk menarik pelanggan.

Promosi dengan media sosial

Media sosial adalah sebuah media online yang penggunanya dapat dengan mudah berpartisipasi, berbagi, dan membuat isi, termasuk blog, jejaring sosial, wiki, forum, dan dunia virtual. Blog, jejaring sosial dan wiki merupakan bentuk media sosial yang paling sering digunakan oleh orang di seluruh dunia. Pengguna internet di Indonesia telah mencapai 63 juta orang. Dari jumlah itu, 95 persen menggunakan Internet untuk mengakses jejaring sosial ( Riu, 2015).

Endorser Menurut Terence A. Shimp (2010) dalam Sidharta, (2014), endorser adalah pendukung iklan atau yang dikenal juga sebagai bintang iklan dalam mendukung iklan produknya. Celebrity endorser didefinisikan sebagai seorang figure yang dikenal baik oleh publik dan memerankan dirinya sebagai konsumen dalam iklan. Selebriti meliputi bintang film maupun 5 bintang televisi, bintang olahraga, penyanyi dan orangorang tertentu lainnya yang berpengaruh (Sidharta, 2014).

Shimp (2003:460) mendefinisikan pengertian dari selebriti yaitu tokoh (aktor, penghibur, atau atlet) yang dikenal masyarakat karena prestasinya di dalam bidang - bidang yang berbeda dari golongan produk yang didukung dan menjadi juru bicara suatu produk.

Atribut merupakan yang dimiliki suatu objek atau individu. Memilih selebriti yang menjadi endorser diperlukan sebuah pertimbangan untuk mewakili produk yang akan di promosikan. Shimp (2014:259)

Perilaku Pembelian Konsumen Menurut Kotler dan Keller (2009: 166) Perilaku konsumen adalah studi tentang bagaimana individu, kelompok, dan organisasi memilih, membeli, menggunakan, dan bagaimana barang, jasa, ide, atau pengalaman untuk memuaskan kebutuhan dan keinginan mereka.

\section{METODE PENELITIAN}

Kerangka konseptual penelitian ini dapat dijelaskan dalam Gambar 3 berikut ini :

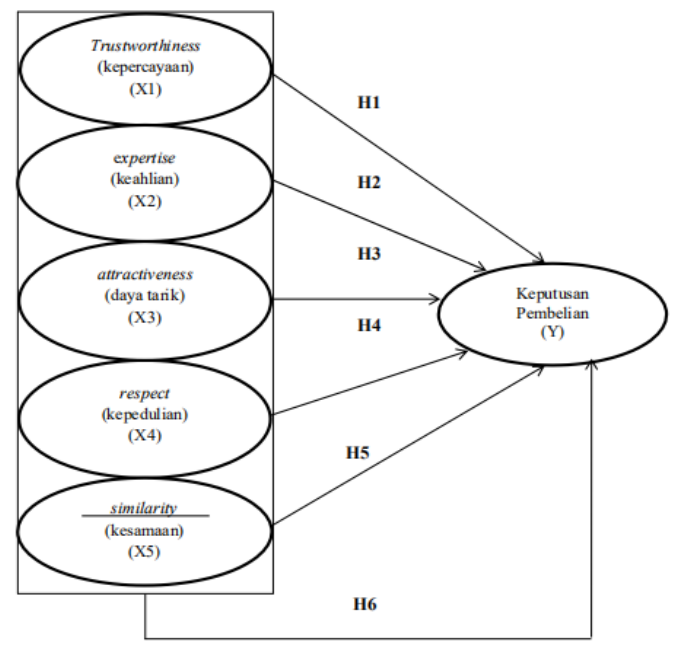

\section{Gambar 3}

Kerangka Pikir

Penelitian ini dilakukan menggunakan google form, yang artinya kuisioner (angket) tersebut langsung diberikan kepada responden menggunakan bantuan google form dan responden akan memilih salah satu alternatif jawaban yang telah tersedia. Pada penelitian ini link google form akan disebar lewat direct messege $(\mathrm{dm})$ pada followers@erigoapparel. Jenis data yang digunakan dalam penelitian ini adalah data primer dan data sekunder. Metode penarikan sampel yang digunakan dalam penelitian ini adalah dengan menggunakan metode Non Probability Sampling. Non Probability Sampling adalah metode pemgambilan 
sampel yang tidak memberikan peluang atau kesempatan yang sama bagi setiap unsur (anggota) populasi untuk dipilih menjadi anggota sampel dengan teknik Purposive Sampling (Sugiyono, 2012).

Analisis deskriptif berguna untuk melihat gambar baik rata-rata maupun penyebaran dari hasil yang telah diperoleh oleh angket (Sugiyono, 2014). Analisis regresi liniear berganda adalah hubungan secara linear antara variabel bebas dan terikat (Prayitno, 2011). dalam analisis regresi berganda memprediksi nilai dari variabel terikat apabila variabel bebas mengalami kenaikan atau penurunan dan untuk mengetahui arah hubungan antara variabel bebas dan varibel terikat apakah masing-masing variabel berhubungan positif atau negatif. Untuk mengetahui pengaruhnya digunakan formulasi sebagai berikut :

$$
\begin{aligned}
\mathrm{Y}= & \mathrm{a}+\mathrm{b} 1 \mathrm{X} 1+\mathrm{b} 2 \mathrm{X} 2+\mathrm{b} 3 \mathrm{X} 3+\mathrm{b} 4 \mathrm{X} 4+ \\
& \mathrm{b} 5 \mathrm{X} 5+\mathrm{e}
\end{aligned}
$$

Uji ketepatan perkiraan $\left(\mathrm{R}^{2}\right)$ dilakukan untuk mendeteksi ketepatan yang baik dalam analisis regresi. Uji hipotesis menggunakan uji $\mathrm{t}$ untuk menguji signifikansi konstanta dan setiap variabel independen akan berpengaruh terhadap variabel dependen dan uji $\mathrm{F}$ pada taraf siginifikansi $5 \%$.

\section{HASIL DAN PEMBAHASAN}

Responden paling banyak berusia 21-25 tahun dengan jumlah 77 orang. Kemudian disusul dengan responden dengan usia $<20$ tahun sebanyak 19 orang. Disusul dengan responden dengan usia 31-35 tahun dengan jumlah 2 orang. Lalu responden dengan usia 25-30 tahun sebanyak 1 orang. Terakhir, responden dengan usia $>35$ tahun dengan jumlah 1 orang. Jumlah responden berjenis kelamin yang berpartisipasi dalam penelitian ini seimbang yaitu 50 orang untuk jenis kelamin laki-laiki dan 50 orang untuk jenis jelamin perempuan.
Berdasarkan pendidikan terakhir adalah SMA sebanyak 66 orang, Sarjana sebanyak 21 orang, Diploma sebanyak 11 orang, SMP sebanyak 2 orang, dan terakhir SD sebanyak 0 orang.

Berdasarkan pekerjaan adalah Pelajar/Mahasiswa sebanyak 63 orang, Lainnya sebanyak 16 orang, Wiraswasta sebanyak 10 orang, Pegawai swasta sebanyak 9 orang, Ibu rumah tangga sebanyak 2 orang dan terakhir PNS sebanyak 0 orang.

Berdasarkan anggaran pembelian adalah untuk anggaran pembelian $\mathrm{Rp}$ 100.000 - Rp 500.000 sebanyak 72 orang, anggaran pembelian Rp 500.000 Rp 1.000.000 sebaanyak 13 orang, anggaran pembelian < Rp 100.000 sebanyak 7 orang, anggaran pembelian Rp 1.000.000 - Rp 1.500.000 sebanyak 4 orang dan terakhir anggaran pembelian > Rp 1.500.000 sebanyak 4 orang.

Hasil penelitian menunjukan bahwa 20 butir item pertanyaan seluruhnya adalah valid, karena corrected item total correlation lebih besar dibandingkan 0.1966, seperti yang dijelaskan (Ghozali, 2012). Dengan demikian indikator pada angket yang digunakan oleh masing-masing variabel dinyatakan valid untuk digunakan sebagai alar ukur dan semua item pertanyaan bisa dilakukan untuk pengujian selanjutnya. Dalam kasus ini berarti semua item yang terdiri dari Trustworthiness (X1), Expertise (X2), Attractiveness (X3), Respect (X4), Similiarity (X5) dan Keputusan pembelian (Y) memenuhi persyaratan validitas secara statistik.

Hasil penelitian menunjukkan bahwa setiap item yang terdiri dari: Trustworthiness (X1), Expertise (X2), Attractiveness (X3), Respect (X4), Similiarity (X5) dan Keputusan pembelian (Y) menghasilkan nilai alpha cronbath 0.60 , sehingga dapat disimpulkan bahwa seluruh variabel yang didukung oleh item pertanyaan 
yang valid memiliki tingkat kehandalan yang tinggi dan reliabel (diterima) sehingga dapat digunakan dalam penelitian ini.

Hasil analisis deskriptif variabel trustworthiness menunjukkan bahwa trustworthiness (3.63), expertise (3.41), attractiveness (3.80), respect (3.88), similarity (3.57), dan keputusan pembelian (4.03), termaksud variabel ke dalam interval skor $3.40 \mathrm{~s} / \mathrm{d} 4.19$ yang berarti pengaruh trustworthiness, expertise, attractiveness, respect, similarity dan keputusan pembelian adalah tinggi.

Tabel 2

Uji Normalitas

One-Sample Kolmogrov-Smirnov Test

\begin{tabular}{llr}
\hline & & \multicolumn{2}{c}{ Unstandardized } \\
& & 100 \\
$\mathrm{~N}$ & & .0000000 \\
Normal Parameters ab & Mean & 3.15697353 \\
& Std. & \\
& Deviation & .073 \\
& Absolute & .049 \\
Most Extreme Difference & Positive & -.073 \\
\hline Kolmogorov-Smirnov Z & Negative & .726 \\
\hline Asymp. Sig (2-tailed) & & .668 \\
\hline
\end{tabular}

Hasil uji normalitas pada tabel 2 diatas menunjukkan bahwa variabel terdistribusi normal, dimana variabel dependen yaitu keputusan pembelian menunjukkan nilai asymp. Sig (2-tailed) $>0.05$ yaitu 0.668 yang berarti data terdistribusi normal.

Tabel 3

Hasil Uji Multikolonieritas

\begin{tabular}{ccc}
\hline \multirow{2}{*}{ Model } & \multicolumn{2}{c}{ Collinearity } \\
& \multicolumn{2}{c}{ Statistics } \\
\cline { 2 - 3 } & Tolerance & VIF \\
\hline (Constant) & .288 & 3.470 \\
trustworthiness & .503 & 1.988 \\
expertise & .316 & 3.167 \\
attractiveness & .373 & 2.680 \\
respect & .559 & 1.789 \\
similarity & .79
\end{tabular}

Hasil Uji Multikolonieritas pada

tabel 3 diatas menunjukkan bahwa hasil perhitungan menunjukkan bahwa tidak ada terdapat variabel yang mempunyai nilai tolerance $\leq 0.10$. selain itu tidak terdapat variabel dengan nilai VIF tidak $\geq 10$. dapat disimpulkan bahwa tidak terjadi multikolonieritas dalam penelitian ini.

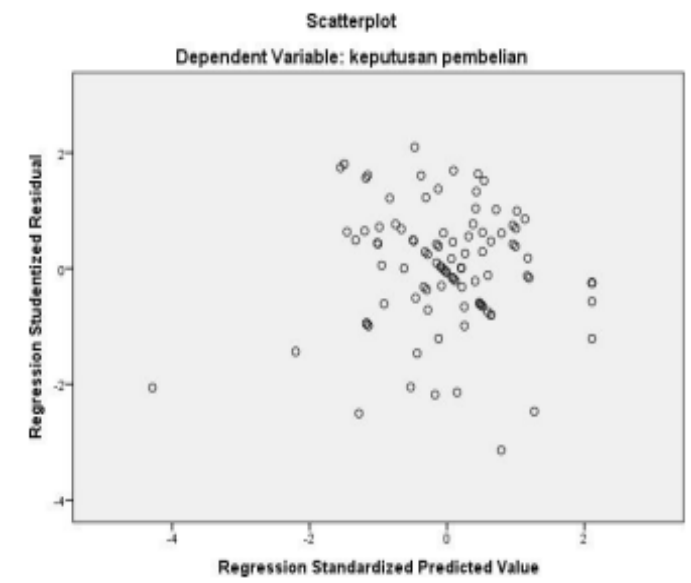

Gambar 4

Hasil Uji Heterokedastisitas

Hasil Uji Heterokedastisitas pada gambar 4 diatas menunjukkan bahwa titik-titik menyebar secara acak, baik tersebar diatas maupun dibawah titik 0 (nol) pada sumbu Y. Penyebaran titiktitik data tidak membentuk pola tertentu, sehingga dapat disimpulkan bahwa tidak terjadi masalah heterokedastisitas, melainkan homokedastisitas, dan uji asumsi klasik telah terpenuhi.

Tabel 4

Hasil Analisis Linier Berganda

\begin{tabular}{cccccc}
\hline \multirow{2}{*}{ Model } & \multicolumn{2}{c}{$\begin{array}{c}\text { Unstandardized } \\
\text { Coefficients }\end{array}$} & $\begin{array}{c}\text { Standardizec } \\
\text { Coefficients }\end{array}$ & t & Sig \\
\cline { 2 - 4 } & B & $\begin{array}{c}\text { Std. } \\
\text { Eror }\end{array}$ & Beta & & \\
\cline { 2 - 4 } (Constant) & 6.423 & 2.132 & & 3.013 & .003 \\
trustworthiness & .108 & .259 & .053 & .416 & .678 \\
expertise & -.073 & .202 & -.035 & -.363 & .717 \\
attractiveness & .914 & .324 & .342 & 2.818 & .006 \\
respect & .594 & .353 & .188 & 1.684 & .095 \\
similarity & 670 & .186 & 329 & 3.610 & .000 \\
\hline \multicolumn{5}{r}{ Hasil uji analisis linier berganda }
\end{tabular}
pada tabel 4 dapat diketahui interpretasi persamaan diatas sebagai berikut : $\mathrm{Y}=\mathrm{a}+\beta 1 \mathrm{X} 1+\beta 2 \mathrm{X} 2+\beta 3 \mathrm{X} 3+\beta 4 \mathrm{X} 4+$ $\beta 5 \mathrm{X} 5+\mathrm{e}$ 
$\mathrm{Y}=6.432+0.108 \mathrm{X} 1+0.073 \mathrm{X} 2+0.914$ $\mathrm{X} 3+0.594 \mathrm{X} 4+0.670 \mathrm{X} 5+$ ę

1.Nilai konstanta dari persamaan diatas adalah 6.423. hal ini menunjukkan bahwa tanpa adanya variabel bebas yaitu trustworthiness, expertise, attractiveness, respect, dan similarity maka keputusan pembelian (Y) nilai positif sebasar 6.423 .

2.Trusworthiness (X1) memiliki koefisien regresi positif sebesar 0.108 . hal ini menunjukkan trustworthiness memiliki hubungan positif dengan keputusan pembelian.

3.Expertise (X2) memiliki koefisien negatif sebesar -0.073. hal ini menunjukkan expertise memiliki hubungan negatif dengan keputusan pembelian.

4.Attractiveness (X3) memiliki koefisien regresi positif sebesar 0.914 . hal ini menunjukkan attractiveness memiliki hubungan positif dengan keputusan pembelian.

5.Respect (X4) memiliki koefisien regresi positif sebesar 0.670 . hal ini menunjukkan respect memiliki hubungan positif dengan keputusan pembelian.

6. Similarity (X5) memiiki koefisien regresi positif sebesar 0.670 . hal ini menunjukkan similarity memiliki hubungan positif dengan keputusan pembelian.

\section{Tabel 5}

Hasil Uji t

\begin{tabular}{cccccc}
\hline \multirow{2}{*}{ Model } & $\begin{array}{c}\text { Unstandardized } \\
\text { Coefficients }\end{array}$ & $\begin{array}{c}\text { Standardizec } \\
\text { Coefficients }\end{array}$ & $\mathrm{t}$ & Sig \\
\cline { 2 - 4 } & $\mathrm{B}$ & $\begin{array}{c}\text { Std. } \\
\text { Eror }\end{array}$ & Beta & & \\
\cline { 2 - 5 } (Constant) & 6.423 & 2.132 & & 3.013 & .003 \\
trustworthiness & .108 & .259 & .053 & .416 & .678 \\
expertise & -.073 & .202 & -.035 & -.363 & .717 \\
attractiveness & .914 & .324 & .342 & 2.818 & .006 \\
respect & .594 & .353 & .188 & 1.684 & .095 \\
similarity & 670 & .186 & 329 & 3.610 & .000 \\
\hline
\end{tabular}

Hasil uji $t$ pada tabel 5 menunjukkan nilai $t$ hitung dan nilai signifikan masing-masing variabel.
Untuk mendapatkan hasil dari uji t maka nilai t hitung akan dibandingkan dengan nilai $t$ tabel dimana jumlah sampel $(n)=$ 100 , jumlah variabel bebas $(\mathrm{k})=5$ dan nilai signifikan 0.05 . didapat $\mathrm{t}$ tabel 1.985. Dari hasil yag diperolah maka dapat ditarik kesimpulan sebagai berikut: 1. Trustworthiness (X1) memiliki nilai $\mathrm{t}$ hitung positif 0.416 dannilai t tabel sebesar 1.985 dapat disimpulkan bahwa trustworthiness berpengaruh negatif dan tidak signifikan terhadap keputusan pembelian.

2. Expertise (X2) memiliki nilai t hitung negatif -0.363 dan nilai ttabel sebesar 1.985 dapat disimpulkan bahwa expertise berpengaruh negatif dan tidak signifikan terhadap keputusan pembelian.

3. Attractiveness (X3) memiliki t hitung positif 2.818 dan nilai t tabel sebesar 1.985 dapat disimpulkan bahwa attractiveness berpengaruh positif dan signifikan terhadap keputusan pembelian.

4. Respect (X4) memiliki t hitung positif 1.684 dan nilai t tabel sebesar 1.985 dapat disimpulkan bahwa respect berpengaruh negatif dan tidak signifikan terhadap keputusan pembelian.

5. Similarity (X5) memiliki t hitung positif 3.610 dan nilai t tabel sebesar 1.985 dapat disimpulkan bahwa respect berpengaruh positif dan signifikan terhadap keputusan pembelian.

Tabel 6

Hasil Uji F

\begin{tabular}{cccccc}
\hline Model & $\begin{array}{c}\text { Sum of } \\
\text { Squares }\end{array}$ & df & $\begin{array}{c}\text { Mean } \\
\text { Square }\end{array}$ & $\mathbf{F}$ & Sig. \\
\hline Regression & 1267.028 & 5 & 253.406 & 24.142 & $.000^{\mathrm{b}}$ \\
Residual & 986.682 & 94 & 10.497 & & \\
Total & 2253.710 & 99 & & & \\
\hline
\end{tabular}

Hasil uji f pada tabel 6 diatas didapat nilai f hitung positif 24.142 dan nilai signifikan 0.000. Dari hasil yang didapat maka diperoleh $\mathrm{f}$ hitung $>\mathrm{f}$ tabel 
$=24.142>$ 2.31. Sementara nilai signifikan $0.000<0.05$. maka H0 ditolak Ha diterima. Maka dapat disimpulkan bahwa Celebrity endorser (trustworthiness, expertise, attractiveness, respect dan similarity) secara simultan berpengaruh positif dan signifikan terhadap keputusan pembelian.

Tabel 7

Hasil Analisa Koefisien Determinasi

\begin{tabular}{ccccc}
\hline Model & $\mathbf{R}$ & $\begin{array}{c}\mathbf{R} \\
\text { Squares }\end{array}$ & $\begin{array}{c}\text { Adjusted } \\
\text { R Square }\end{array}$ & $\begin{array}{c}\text { Std. Eror of } \\
\text { the Estimate }\end{array}$ \\
\hline 1 & $.750^{\mathrm{a}}$ & .562 & .539 & 3.240 \\
\hline
\end{tabular}

Hasil uji koefisien determinasi pada tabel 7 diatas sebesar 0.539 , hal ini berarti 53.9\% variabel keputusan pembelian dapat dijelaskan oleh variabel trustworthiness, expertise, attractiveness, respect, dan similarity, sisanya $(100 \%-53.9 \%=46.1 \%)$ dijelaskan oleh variabel lain yang terkait dengan keputusan pembelian seperti desain produk, promosi menarik, dan lainnya yang tidak terdapat dalam penelitian ini.

\section{SIMPULAN}

Berdasarkan penelitian yang telah dilakukan, maka dapat ditarik kesimpulan bahwa:

1. variabel trustworthiness secara simultan memiliki pengaruh negatif dan tidak signifikan terhadap keputusan pembelian Produk Erigo melalu Instagram.

2. variabel expertise secara simultan memiliki pengaruh negatif dan tidak signifikan terhadap keputusan pembelian pada produk Erigo melalui Instagram.

3. variabel attractiveness secara simultan memiliki pengaruh positif dan signifikan terhadap keputusan pembelian pada produk Erigo melalui Instagram.

4. variabel respect secara simultan memiliki pengaruh negatif dan tidak signifikan terhadap keputusan pembelian pada produk Erigo melalui Instagram.

5. variabel similarity secara simultan memiliki pengaruh positif dan signifikan terhadap keputusan pembelian pada produk Erigo melalui Instagram.

\section{DAFTAR PUSTAKA}

Alsarayreh, Mohammad N., Jawabreh, Omar A. A. (2011). Tourism Promotion through the Internet (Websites) (Jordan as a Case Study). Asian Social Science. Vol. 7. No. 6. Diakses tanggal 20 februari 2019.

Darmansyah, Muhartini Salim, Syamsul Bachri, S. (2014). Pengaruh Celebrity Endorser terhadap Keputusan Pembelian Produk di Indonesia (Penelitian Online). Jurnal Aplikasi Manajemen Fakultas Ekonomi Manajemen Universitas Bengkulu : Vol. 12, No. 2, Hal. 230-238. Ineka Cipta. https://jurnaljam.ub.ac.id/index.ph p/jam/article/view/644, diakses 28 November 2018.

E-marketer Team. (2016). Instagram Users in Indonesia Follow Fashion.

https://www.emarketer.com/Articl e/Instagram-Users-Indonesia-

Follow-Fashion/1 013618, diakese 20 Januari 2019.

Ghozali, I. (2011). Aplikasi Analisis Multivariate Dengan Program SPSS. Semarang: Badan Penerbit Universitas Diponegoro.

Hair, J.F., Black, W.C., Babin, BJ., and Anderson, R.E. 2010. Multivariate Data Analysis, 7 tahun edition.NJ: Pearson Prentice Hall.

Kotler dan Keller. 2009. Manajemen Pemasaran. Jilid I. Edisi ke 13. Jakarta: Erlangga.

Musay, F. (2013). Pengaruh Brand Image terhadap Keputusan Pembelian Survei Pada Konsumen 
KFC Kawi Malang. Malang: Universitas Brawijaya. https://administrasibisnis.studentjo urnal.ub.ac.id/index.php/jab/article /view/141, diakses 29 November 2018

Mubarak, N. (2018). Pengaruh Celebrity Endorser pada Media Sosial Instagram terhadap Keputusan Pembelian (survei online pada konsumen produk Erigo Jakarta melalui Instagram). Malang: Universitas Brawijaya. http://administrasibisnis.studentjou rnal.ub.ac.id/index.php/jab/article/ view/ 2645, diakses 30 November 2018.

Osman, S., Fah, Benjamin. C. Y., dan Foon, Yeoh. S. (2011). Simulation of Sales Promotions towards Buying Behavior among University Students, International Journal of marketing studies. vol. 3. no. 3. pp. $78-88$

Parengkuan,dkk. (2013). Analisis Pengaruh Brand Image dan Celebrity Endorser terhadap Keputusan Pembelian Produk Shampo Head and Shoulder di 21 Mart Manado. Jurnal EMBA, Vol 2. No 3 September 2014, Hal 1792-1802. ISSN 2303-1174. https://ejournal.unsrat.ac.id/index.p $\mathrm{hp} / \mathrm{emba} /$ article/view/5972, diakses 05 Desember 2018.

Priyatno, D. (2011). Teknik Mudah dan Cepat Melakukan Analisis Data Penelitian Dengan SPSS. Yogyakarta: Gava Media.

Rahima. (2018). Pengaruh Celebrity Endorser di Media Sosial Instagram dalam Promosi Produk Hijab terhadap Minat Beli Konsumen (studi kasus pada akun Instagram @wiriamaeazzahra). Mataram : STMIK Bumigora. https://conferences.uinmalang.ac.id/index.php/semnasfe/a rticle/download/712/256, diakses 10 Desember 2018.

Riu, Isma. A. (2015). Use of Social Media as a Media Promotion for Small and Medium Enterprises. Information Management and Business Review. Vol. 7. No. 4. Sari, Devilia. (2014). Pengaruh Celebrity Endorser dan Word of Mouth terhadap Keputusan Pembelian Produk Sweater Online Shop Alco di Media Sosial Instagram. Bandung : Universitas Telkom.

https://jurnal.stiepas.ac.id/index.ph $\mathrm{p} / /$ jebe/article/view/201,

Sidharta, Cyntia (2014). Penggunaan Anggun C. Sasmi sebagai Celebrity Endorser dalam iklan Pantene versi "Bersinarlah Bersama Anggun". E-komunikasi. Vol. 2. No.3.

Shimp, Terence A. 2003. Periklanan dan Promosi : Aspek Tambahan Komunikasi Pemasaran Terpadu. Alih Bahasa Revyani Syahrial dan Dyah Anikasari. Edisi 5. Jilid 1. Jakarta : Erlangga.

Sugiyono. (2012). Metode Penelitian Kuantitatif, Kualitatif, dan R\&D. Bandung : Alfabeta. (2014). Metode Penelitian Kuantitatif, Kualitatif, dan Kombinasi (Mixed Methods). Bandung: Alfabeta.

Tim Kompas. (2018). Pengguna Aktif Instagram Tembus 1 Miliar. https://kompas.com/read/2018/06/ 21/10280037/juni-2018-penggunaaktif-instagar m-tembus-1-miliar. Diakses pasa tanggal 18 Januari 2019.

Tim Tempo. (2018). Pengguna Aktif Instagram Naik Pesat. https://tempo.co/read/548613/peng guna-aktif-instagram-naikpesat/full\&view=ok. Diakses 18 Januari 2019 
Tjipto, F. 2012. Service Management Mewujudkan Layanan Prima. Yogyakarta : Andi.

Umar, H. (2011). Metode Penelitian untuk Skripsi dan Tesis Bisnis Edisi 11. Jakarta : PT Raja Grafindo Persada. 